\title{
Semantic and Structural Characteristics of Impersonal Sentences with Introductory "it"
}

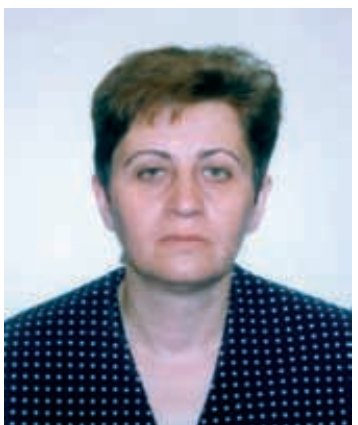

Anahit Hovhannisian

T anguage learners face the monumental task of Lacquiring new vocabulary, syntactic patterns and phonology, as well as the indispensability of developing discourse competence. Without the knowledge of discourse structure and sociocultural patterns of the target language, the strategies acquired as part of their first language development may be inappropriate for the second language setting and may lead to communicative difficulties and misunderstandings. Therefore, one of the goals of second language teaching is to expose learners to different discourse patterns in different texts and interactions. We should more closely examine the patterns of language use in the classroom and the effect these established patterns have on the learning process.

The problem is how to analyze these patterns. One of the approaches of speech pattern analysis is dynamic semantics.

In recent decades semantic theory has been marked by a continuing shift from a static view of meaning to a dynamic one. Dynamic semantics is a shift from sentence semantics to discourse semantics. The analysis moves from isolated sentences to larger units of discourse and text. The present theory (dynamic semantics) has developed as a modification of dynamic logic and treats the meaning of a sentence as the relation between its "input" and "output" referential links.

The increasing interest in extending semantic analyses from isolated sentences to larger units of discourse has forced the intensive study of speech patterns.

We should consider sentences of the type

It is important to go. (1)

It is important that he is coming/he come. (2)

The main goal of this article is to reveal the structural and meaningful peculiarities of sentences of the type It is ... that .... where that introduces an embedded noun-clause and the extraposed it is is followed by an adjective.

It is commonly acknowledged that the existence of personal and impersonal models is the result of different psychological perceptions of the outer world. Being built on the general model "subject- predicate-object"(S-P-O), English impersonal sentences, including it as a pseudo-personal subject, have the following grammatical peculiarities: 1. contrary to the definite-personal subject, it has no indication towards any concretely 
named object and, therefore, has no denotational correlation.

2. contrary to the indefinitc-personal subject expressed in such morphological indicators as we, you, they and numerical one, the pseudo-personal it does not contain any generalized referential meaning defining the whole class of homogeneous subject, ef: One should obey the rules; If you stand with your back to the wall .... and It is snowing; It rains etc. It is symptomatic that the sentences containing the verbs of the type to rain. to snow, to drizzle, etc. are perceived to have no subject (the corresponding Russian and Armenian constructions have no subject whatsoever) in Indo-European languages. Since Modern English is a language of formalized structures, it is but natural, therefore, that for grammatical unification the element it was introduced as a pseudo-personal subject.

The logical, psychological and grammatical division is not homogeneous here. Grammatically, it serves to divide information into centers of primary and secondary proximity. Psychologically, it is the starting point from which the information about the fact begins.

Thus it is clear that the grammatical subject is the pronoun, the logical subject is the complement, the psychological topic is the complex of the grammatical subject and predicate, the latter being the sentantic center of the sentence.

There is a sharp controversy between the seeming semantic insignificance of the grammatical subject (introduced by the demonstrative pronoun it) and the semantic center of the sentence of the type $I t$ is difficult (important) to...

It is not merely an introductory and meaningless appendix of the semantic center. On the contrary. it carries out a most essential tunction, fixing certain spatial connections which are dependent upon the simulaneity, priority or further succession of the object of thought.

The subject it is completely desemanticized. And since any language phenomenon is a unity of the abstract and the concrete, it is natural that the abstract nature of the grammatical subject must be compensated by the concreteness of the two forms bound with it (predicate and object).

As for subject-predicate correlation, like any verb the predicate to be determines the temporal evaluation of the subject (its temporal fumction: present, past or future) and it does not carry any additional semantic charge. This fact accounts for

1. the use of $t o$ be as a predicate in all these models:

2. representing time correlation only in the form of imperfective present, past or future (not burdened, as a rule, by any continuous and perfect distinctions).

The predicate is connected with the subject by grammatical but not by semantic ties. Logically, it brings the subject and object together but, grammatically. it separates both types. The subject and predicate form a peculiarly complete spatial-temporal complex. in which the predicate functioning as an independent element of the sentence possesses:

1. grammatical completeness representing a simple and not a compound predicate

2. meaningful conmection of two notions - of space limitation rendered by the subject and of semantic contents rendered by the object

3. dependence of the subject on the object in certain space-time coordinates. 
As has been mentioned above, in both models it loses its concrete demonstrative meaning acquiring the space-time distinction of the object. The subject directs the thought to the object of the sentence and acquires additional shades of meaning through it.

It is natural that such a subject, unlike the predicate, cannot be indifferent to the infonmative aspect of the object. In the second construction the object, which is both the grammatical complement and the logical subject of the statement, is not informatively exhaustive enough and, therefore, the semantic need is satisfied through the subordinate clause.

It is not incidental that the second logical notion wherein lies the center of the semantic stress is as a rule a word of modal character like possible, difficul, etc.

In this paper I want to identify some semantic classes of evaluative attributes for propositions and proposals, which appear to be the only ones allowed in English. I will illustrate their use from a corpus of newspaper editorials and characterize some interesting discourse phenomena for further study. From the larger corpus of newspaper editorials culled from what was available at the time in digital files on the Internet, I selected for close analysis editorials from the newspapers: The New York Times, The Boston Globe, The Irish Times (of Dublin), Word Politics, etc. All these newspapers address from middle to upper-middle class readerships and they employ a wide range of lexico-grammatical and discourse devices, including various "grammatical inetaphors" for modality.

If we consider occurrences of sentences or clauses of the form $I t$ is ...that ... where that introduces an embedded noun-clause, and the extraposed it is is followed by an objective, we shall see that the adjectives which occur in this frame fall into a small number of semantic clauses, all of which are in some basic sense evaluative epithets ${ }^{1}$. If we apply a systematic-functional analysis to this structure, we realize that in most cases the adjective is an attribute and the noun clause presents a fact or a proposition (if realis), or some sort of proposal or possibility (if irrealis).

Cf: It is essential that he is leaving/may leave (realis).

It is essential that he leave (irrealis).

It is quite evident that the lexical item (essential), when evaluating a proposal irrealis, realizes a different semantic dimension which is different from the same item evaluating a proposition assumed to be true. English sometimes requires whether in place of that and also allows non-finite complement clauses introduced by to or for...to. e.g. It was so inportant to my mother that we be not brought up as "cheap" Irish. (Conan O'Brien, 2001-01-23)

So what are the possible evaluative attributes of propositions and proposals?

1. Importance/ significance

a) It is very important that he is coming/may come.

b) It is important we take a hard, clear look... Not at some simple world, either of universal good will or of universal hostility, but at the complex, changing, and sometimes dangerous world that really exists. (Jimmy Carter, President of the U.S., 1980 "World Politics", New York 2001. p.26) 
2. Normativity

a) It is quite necessary John is arriving.

b) ...it is necessary that economic interdependence have a political foundation. (World Politics, 200 I, p.253)

3. Urgency

a) It is extremely urgent that he return.

b) It is extremely urgent that we talk with you right now, sir. (from the series "The XFiles" 2001-01-06)

4. Desirability

It is really wonderful that they are joining us.

In order to control intersymbol interference, it is desirable that l's not be close together, or equivalently that runs of 0 's not be too short. ("Symbolic Dynamics and Coding Applications", Plenary Lecture at the 1995 IEEE International Symposium on Information Theory)

5. Warrantability/Probability

a) It is quite possible that they are leaving/may leave.

b) It is quite possible that they leave.

6. Obviousness

It is perfectly understandable that he is joining us/may join us.

7. Humorousness/seriousness

a) It is hilarious that Jack is coming/may come.

b) It is very serious that Jack is coming/may come.

As we can see, the evaluative attributes may express a complementary negative meaning:

It is wonderful that.... It is really horrible that...

It is very important that....- It is really quite trivial that...2

How is the logical subject (gramnatical complement) formed in the English language? What tense forms are used in the embedded clauses for expressing real and unreal actions?

From the point of view of contrastive grammar we can make a very important statement in this connection: in English realis the verbal form used in the embedded clause is manifested in only one grammatical form - the Present Continuous - and the Present Subjunctive in irrealis.

It becomes also apparent that the corresponding verbal forms in the Armenian language are the Present Indicative as a correlative tense form of the Present Continuous and the Present form of the so-called Subjunctive and Conditional Moods as correlatives of the Subjunctive Present.

Thus, we arrive at the conclusion that in the Armenian language the grammatical forms of the future tense are closely intertwined with modality, as future statements are always connected with a certain oblique modality in contrast with the present and past which are quite naturally used with "directly modal" or "indicative meaning".

The analysis of impersonal sentences also shows the close kinship between the semantics of propositional evaluations and modality. 
Cf.: Jolm must be coming (modal auxiliary).

John is certainly coming (modal adverb).

It is certain that John is coming (evalualive epithet / objective orientation).

I am certain that John is coming (evaluative epithet / subjective orientation).

These variants are not perfectly synonymous in their total meaning potentiais, of course (mist be , may be, certainly, probably, etc.).Thus, in the last two examples we have the same evaluative epithet certain but the shades of the meanings are different: in the first sentence the meaning of obviousness is combined with that of objective orientation, whereas in the second example obviousness and subjective orientations create the meaning of the evaluative attribute.

As has been mentioned above, seeking a small test corpus, where I would be likely to find high-density evaluations, 1 chose to look at newspaper editorials. Defining the semantic range of evaluative attributes, 1 also wanted to see how frequently each dimension was realized in this typically evaluative register to indicate

Desirability $47 \%$ (Desirability is more than twice as common as Warrantability).

Warrantability/Probability $17 \%$

Normativity/Obligation $14 \%$

Importance $6 \%$

Seriousness/Humour $0 \%$

Frequency of types of grammatical realization

Attributive adjectives of quality $16 \%$

Finite verbs $22 \%$

Modals 7\%

Abstract nouns 12\%

Concrete nouns $2 \%$.

\section{Notes:}

1. Halliday M.A.R. An Introduction to Functional Grammar. London, Edward Amold, 1985.

2. M.A.R. Halliday recognizes evaluative attributes of proposition and proposals as one of the "interpersonal grammatical metaphors".

\section{References:}

1. Leech Geoffrey, Deuchar M. and Hoogenraad R. English Grammar for Today. New York, Palgrave, 1982.

2. Robert D. Van Valin, J.K. An Introduction to Syntax. Cambridge University Press, 2001. 


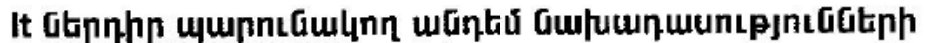

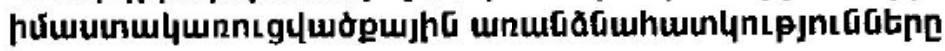

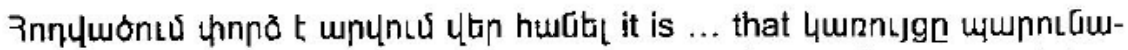

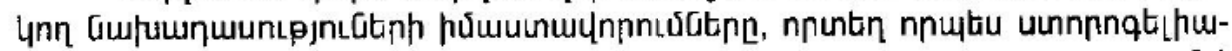

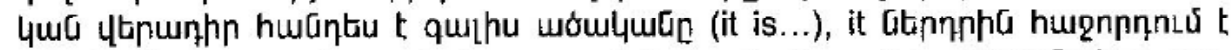

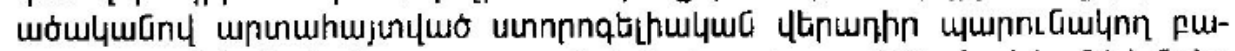

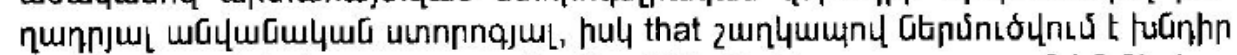

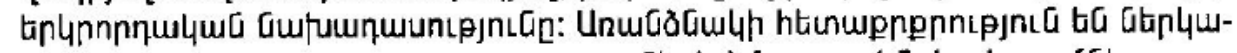

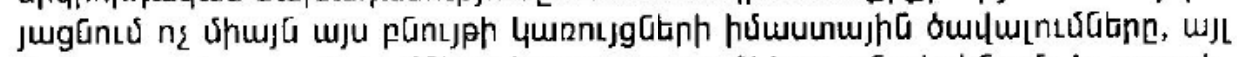

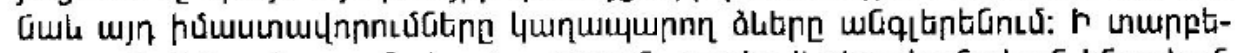

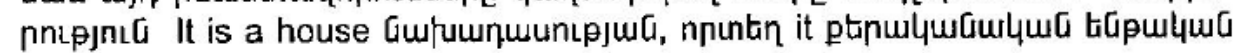

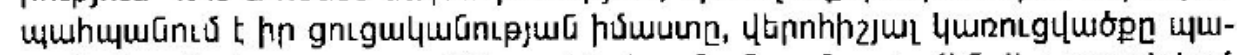

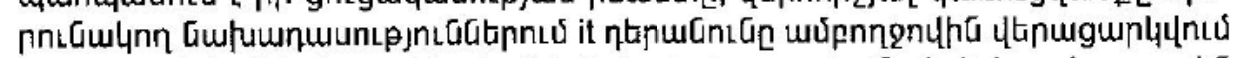

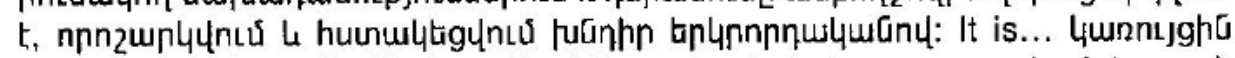

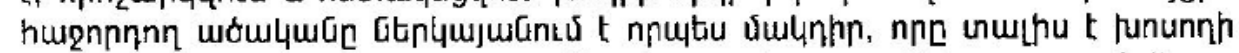

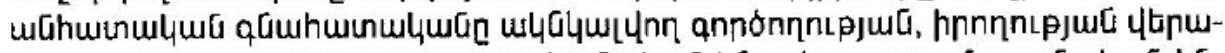

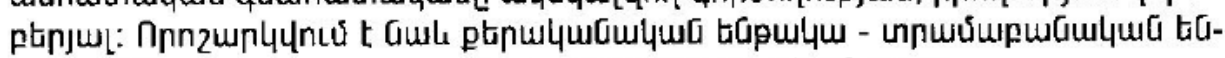

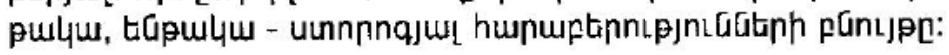

